OPEN ACCESS

Edited by:

Peter J. Lammers,

Arizona State University, United States

Reviewed by:

Justin Findinier,

Carnegie Institution for Science,

United States

Ansgar Gruber,

Academy of Sciences of the Czech

Republic (ASCR), Czechia

*Correspondence:

Zhiyong Li

zyli@sjtu.edu.cn

Specialty section:

This article was submitted to Marine and Freshwater Plants,

a section of the journal

Frontiers in Plant Science

Received: 27 July 2020 Accepted: 21 October 2020 Published: 17 November 2020

Citation:

Gong S, Jin X, Xiao Y and Li Z (2020) Ocean Acidification and Warming Lead to Increased Growth and Altered Chloroplast Morphology in the Thermo-Tolerant Alga Symbiochlorum hainanensis.

Front. Plant Sci. 11:585202. doi: $10.3389 / \mathrm{fp} / \mathrm{s} .2020 .585202$

\section{Ocean Acidification and Warming Lead to Increased Growth and Altered Chloroplast Morphology in the Thermo-Tolerant Alga Symbiochlorum hainanensis}

\author{
Sanqiang Gong ${ }^{1,2,3}$, Xuejie Jin' ${ }^{2,3}$, Yilin Xiao ${ }^{1}$ and Zhiyong $\mathrm{Li}^{1 *}$ \\ ' Marine Biotechnology Laboratory, State Key Laboratory of Microbial Metabolism and School of Life Sciences \\ and Biotechnology, Shanghai Jiao Tong University, Shanghai, China, ${ }^{2}$ Key Laboratory of Tropical Marine Bio-Resources \\ and Ecology, Guangdong Provincial Key Laboratory of Applied Marine Biology, South China Sea Institute of Oceanology, \\ Chinese Academy of Sciences, Guangzhou, China, ${ }^{3}$ Southern Marine Science and Engineering Guangdong Laboratory, \\ Guangzhou, China
}

Ocean acidification and warming affect the growth and predominance of algae. However, the effects of ocean acidification and warming on the growth and gene transcription of thermo-tolerant algae are poorly understood. Here we determined the effects of elevated temperature $(H)$ and acidification $(A)$ on a recently discovered coral-associated thermo-tolerant alga Symbiochlorum hainanensis by culturing it under two temperature settings $\left(26.0\right.$ and $\left.32.0^{\circ} \mathrm{C}\right)$ crossed with two $\mathrm{pH}$ levels $(8.16$ and 7.81). The results showed that the growth of $S$. hainanensis was positively affected by $\mathrm{H}, \mathrm{A}$, and the combined treatment $(\mathrm{AH})$. However, no superimposition effect of $\mathrm{H}$ and $\mathrm{A}$ on the growth of $\mathrm{S}$. hainanensis was observed under $\mathrm{AH}$. The analysis of chlorophyll fluorescence, pigment content, and subcellular morphology indicated that the chloroplast morphogenesis (enlargement) along with the increase of chlorophyll fluorescence and pigment content of $S$. hainanensis might be a universal mechanism for promoting the growth of $S$. hainanensis. Transcriptomic profiles revealed the effect of elevated temperature on the response of $S$. hainanensis to acidification involved in the down-regulation of photosynthesis- and carbohydrate metabolism-related genes but not the up-regulation of genes related to antioxidant and ubiquitination processes. Overall, this study firstly reports the growth, morphology, and molecular response of the thermo-tolerant alga $S$. hainanensis to future climate changes, suggesting the predominance of S. hainanensis in its associated corals and/or coral reefs in the future.

Keywords: acidification, warming, thermophilic, Symbiochlorum hainanensis, coral reef algae

\section{INTRODUCTION}

Ocean acidification and warming have led to shifts in seawater chemistry and carbonate saturation, which will potentially affect the physiology, behavior, and predominance of a range of organisms in marine ecosystems (Hoegh-Guldberg and Bruno, 2010). In recent decades, the mean pH value of surface seawater has declined by an average of 0.1 units, owing to the uptake of $\mathrm{CO}_{2}$ 
(Feely et al., 2009). Further decreases of 0.3-0.5 pH units and warming of $1-7^{\circ} \mathrm{C}$ are projected to occur by the end of this century (Feely et al., 2009; IPCC, 2014).

As primary producers, marine photosynthetic algae account for approximately half of global photosynthetic carbon fixation (Falkowski and Raven, 2013). Increasing evidence shows that ocean acidification influences the growth and/or gene transcription of algae, and the responses of algae to acidification are modulated by temperature, light, UV, and nutrient availability (Gao and Campbell, 2014; Gao et al., 2017; Boyd et al., 2018). For example, acidification may enhance the $\mathrm{N}_{2}$ fixation activity of cyanobacteria, but trace metal availability may neutralize or even reverse this effect (Zhang et al., 2019). Elevated $\mathrm{CO}_{2}$ enhances the growth of diatoms at low levels of sunlight but inhibits their growth at high levels (Gao et al., 2019). For most calcifying macroalgae, acidification under elevated solar $\mathrm{UV}$ and/or elevated temperature reduces their calcification (Jin et al., 2017; Martin and Hall-Spencer, 2017). Non-calcifying macroalgae, on the other hand, appear to benefit from elevated $\mathrm{CO}_{2}$ and show an enhanced growth rate (Gao et al., 1993; Cornwall et al., 2015, 2017). Furthermore, the geographic distribution and/or predominance of algae are also affected by future ocean acidification and warming conditions (Wernberg et al., 2011). A study of over 20,000 herbarium records of algae collected over 70 years from the Pacific and the Indian oceans around the Australian coast showed that a pole-ward shift of several temperate algal species is already occurring (Wernberg et al., 2011). Acquiring resistant Symbiodiniaceae from the environment or changing the relative abundance of Symbiodiniaceae associated with corals under elevated temperature have been reported (Baker et al., 2004; Fautin and Buddemeier, 2004). One field study provides evidence that acidification can lead to a predominance of macroalgae on reefs (Johnson et al., 2014). Those studies reveal that the response of algae to ocean acidification and warming are species specific, and certain thermophilic and/or stress-tolerant algae might have the ability to acclimate to future global climate changes and become predominant in the future. However, the individual and specifically combined effects of ocean acidification and warming on the growth and gene transcription of the thermophilic and/or stress-tolerant algae in the ocean remain poorly understood.

Symbiochlorum hainanensis, a recently discovered unicellular alga affiliated with Ulvophyceae, is widely associated with corals in the tropical coral reef areas of the South China Sea (SCS), where the annual average temperature is approximately $26^{\circ} \mathrm{C}$ (Gong et al., 2018, 2019). The optimal growth temperature of this alga is approximately $32^{\circ} \mathrm{C}$ (Supplementary Figure 1), which is higher than that of coral-symbiotic Cladocopium spp. (dominant Symbiodiniaceae associated with corals in the SCS; Supplementary Figure 2). Besides that, S. hainanensis can maintain rapid growth when it is cultured at $35^{\circ} \mathrm{C}$ (Supplementary Figure 1). Hence, S. hainanensis is a thermotolerant alga, and we propose that it may outcompete Cladocopium spp. and be the predominant species in coral-algae symbiont areas and/or coral reef areas in the future. However, how it will respond to future ocean acidification and warming conditions is unclear. Therefore, the present study performed a 28-day lab-scale experiment in which $S$. hainanensis was cultured under two temperature settings $\left(\sim 26.0^{\circ} \mathrm{C}, n=3\right.$ and $\sim 32.0^{\circ} \mathrm{C}$, $n=3$ ) crossed with two $\mathrm{pH}$ levels $(\sim 8.16, n=3$ and $\sim 7.81, n=3)$ to mainly explore the growth and the molecular-level response of $S$. hainanensis to the individual and combined effects of future ocean acidification and warming conditions.

\section{MATERIALS AND METHODS}

\section{Cultures and Experimental Setup}

Cultures of S. hainanensis (CCTCC M2018096), isolated from coral species Porites lutea in the tropical reef regions of the SCS (Gong et al., 2018, 2019), were incubated in 250-ml Erlenmeyer flasks with $100 \mathrm{ml}$ autoclaved artificial seawater medium (Formula grade A Reef Sea Salt, Formula, Japan) under an in situ temperature of $26^{\circ} \mathrm{C}$, light intensity of $90 \mu \mathrm{mol}$ photon $\mathrm{m}^{-2} \mathrm{~s}^{-1}$ with a $12-\mathrm{h} / 12-\mathrm{h}$ light/dark cycle. The cultures were shaken at least three times a day. Cells in the mid-exponential phase were collected by centrifugation $(5,000 \mathrm{rpm}$ for $10 \mathrm{~min})$ and washed three times with sterile phosphate-buffered saline. Then, cell pellets were re-suspended in autoclaved artificial seawater medium and used for further experiments.

Cultures of $S$. hainanensis were acclimated to four conditions: (1) $p \mathrm{CO}_{2}$ level $1,000 \mu \mathrm{atm}(\mathrm{pH}=7.81), 26^{\circ} \mathrm{C}(\mathrm{A}, n=3)$, (2) $p \mathrm{CO}_{2}$ level $395 \mu$ atm $(\mathrm{pH}=8.16), 32^{\circ} \mathrm{C}(\mathrm{H}, n=3)$, (3) $p \mathrm{CO}_{2}$ level $1,000 \mu \mathrm{atm}(\mathrm{pH}=7.81), 32^{\circ} \mathrm{C}(\mathrm{AH}, n=3)$, and (4) $p \mathrm{CO}_{2}$ level $395 \mu \mathrm{atm}(\mathrm{pH}=8.16), 26^{\circ} \mathrm{C}(\mathrm{C}, n=3)$. To achieve the different $p \mathrm{CO}_{2} / \mathrm{pH}$ conditions, $1,000-\mathrm{ml}$ Erlenmeyer flasks with $500 \mathrm{ml}$ autoclaved artificial seawater medium were bubbled with sterilized air containing either ambient ( $395 \mu \mathrm{atm}, \mathrm{pH}=8.16)$ or elevated (1,000 $\mu$ atm, $\mathrm{pH}=7.81$, Supplementary Figure 3$) \mathrm{CO}_{2}$ concentrations using outdoor air and $\mathrm{CO}_{2}$ chambers (HP1000G$\mathrm{D}$, China). To achieve the different temperature conditions, the Erlenmeyer flasks were incubated in water baths $\left(26\right.$ or $32^{\circ} \mathrm{C}$, Supplementary Figure 4). For each treatment, triplicate cultures were incubated under cool white fluorescent light intensity of $90 \mu \mathrm{mol}$ photons $\mathrm{m}^{-2} \mathrm{~s}^{-1}$.

\section{Cell Growth and Morphology Observation}

The cell concentration of $S$. hainanensis under the A $(n=3), \mathrm{H}$ $(n=3), \mathrm{AH}(n=3)$, and $\mathrm{C}(n=3)$ conditions was monitored every 2 days by optical density (OD) value at $750 \mathrm{~nm}$ with a UV spectrophotometer (UV-7504, China) at $750 \mathrm{~nm}$. The growth rate was calculated based on the cell concentration variations of S. hainanensis at exponential phase (day 2 to day 24). The dry cell weight in the mid-exponential phase under the $\mathrm{A}(n=3)$, $\mathrm{H}(n=3), \mathrm{AH}(n=3)$, and $\mathrm{C}(n=3)$ conditions was measured by filtering the algal suspension through a pre-dried and preweighted $0.45-\mu \mathrm{m}$ cellulose nitrate membrane filter (Whatman, United States) and drying in an oven at $80^{\circ} \mathrm{C}$ for $24 \mathrm{~h}$.

Chlorophyll fluorescence of $S$. hainanensis under the A $(n=3)$, $\mathrm{H}(n=3), \mathrm{AH}(n=3)$, and $\mathrm{C}(n=3)$ conditions was measured using a Turner fluorometer with the in vivo module (Trilogy, Turner Design, Sunnyvale, CA, United States). Algal cells in the mid-exponential phase under the $\mathrm{A}(n=3), \mathrm{H}(n=3), \mathrm{AH}$ 
$(n=3)$, and $\mathrm{C}(n=3)$ conditions were sampled for chlorophyll $a$, chlorophyll $\mathrm{b}$, and total carotenoids measurements according to the acetone-based method (Dere et al., 1998).

Cells of $S$. hainanensis in the mid-exponential phase under different conditions ( $\mathrm{A}, \mathrm{H}, \mathrm{AH}$, and $\mathrm{C}$ ) were determined based on scanning electron and transmission electron microscopy observations according to our previous study (Gong et al., 2018).

\section{RNA Extraction, Purification, and Sequencing}

Algal cells under the A $(n=3), \mathrm{H}(n=3), \mathrm{AH}(n=3)$, and $\mathrm{C}(n=3)$ conditions were harvested in the mid-exponential phase by centrifugation at $5,000 \mathrm{rpm}$ for $5 \mathrm{~min}$ at $4^{\circ} \mathrm{C}$ for total RNA extraction and RNA-seq. In detail, cell pellets under different conditions were snap-frozen in liquid nitrogen and stored at $-80^{\circ} \mathrm{C}$ before RNA extraction. Total RNA was extracted from algal cells as previously described (Rosic and Hoegh-Guldberg, 2010). The RNA quantity and integrity were analyzed using a NanoDrop ND-1000 spectrometer (Wilmington, DE, United States) and an Agilent 2100 Bioanalyzer (Santa Clara, CA, United States). RNA samples with high purity (OD260/280 between 1.8 and 2.2) and high integrity (RNA integrity number $>8$ ) were used for cDNA library construction. The size and the concentration of the cDNA libraries were determined by the Agilent 2100 Bioanalyzer (Santa Clara, CA, United States). All cDNA libraries were layered on a separate Illumina flow cell and sequenced using Illumina HiSeq 2000 (Illumina, Inc.). The raw sequence data produced in this study were deposited in the Sequence Read Archive (PRJNA662215) at the National Center for Biotechnology Information (NCBI).

\section{Quality Control and Short Read Assembly}

Raw RNA-Seq reads under the $\mathrm{A}(n=3), \mathrm{H}(n=3)$, $\mathrm{AH}(n=3)$, and $\mathrm{C}(n=3)$ conditions were processed using Trimmomatic v0.33 for trimming adapters as well as low-quality bases from the ends of the reads (Bolger et al., 2014). Poor-quality reads with average Phred quality score $<20$ and reads with lengths $<55$ were filtered out. The resulting set of good quality reads was then assembled with Trinity v2.1.1 software using default parameters (Grabherr et al., 2011; Haas et al., 2013). The assembly validation was performed using Bowtie2 aligner, where the filtered reads were mapped back to the assembled unigenes. Furthermore, non-redundant unigenes were retrieved with the aid of CDHIT-EST software ${ }^{1}$ that clustered the unigenes with an identity parameter of $95 \%$.

\section{Functional Annotation and Identification of Differentially Transcribed Genes}

The de novo-assembled unigenes were searched against NCBI's non-redundant protein and Swiss-Prot database using the BLASTX algorithm with an $e$-value cutoff of $10^{-5}$. Unigenes with significant matches were annotated using the Blast2GO

\footnotetext{
${ }^{1}$ http://weizhongli-lab.org/cd-hit/
}

platform (Conesa et al., 2005). Additional annotations were obtained through the Kyoto Encyclopedia of Genes and Genomes (KEGG) database through the KEGG Automatic Annotation Server (v1.6a) (Moriya et al., 2007). The cluster in the eggNOG database was employed to classify and group the putative and definitively identified proteins. The expression quantity of each unigene (fragments per kilobase of exon model per million mapped fragments) was estimated using RSEM (Li and Dewey, 2011). Differentially transcribed genes were selected using edge $\mathrm{R}$ as the method of choice (Robinson et al., 2010). Fold change differences were considered significant when a $P$-value $<0.01$ was achieved based on Benjamin and Hochberg's false discovery rate procedure. A correlation analysis of differentially transcribed genes among different conditions was performed using the program package in the $\mathrm{R}$ software package ( $\mathrm{R}$ 3.1.2). BrayCurtis dissimilarity-based principal coordinate analysis (PCoA) pictures of differentially transcribed genes were drawn using Primer- $\mathrm{e}^{2}$ for comparing differentially expressed genes under different conditions.

\section{Quantitative Polymerase Chain Reaction}

To validate the RNA-seq results, the expression level of 17 differentially transcribed genes under the $\mathrm{A}(n=3), \mathrm{H}(n=3), \mathrm{AH}$ $(n=3)$, and $\mathrm{C}(n=3)$ conditions was measured using quantitative PCR (qPCR). The list of genes and primers is available in the electronic Supplementary Material (Supplementary Table 1). Complementary DNA was synthesized from $1 \mu \mathrm{g}$ of total RNA, and qPCR was performed with an ABI ViiA 7 Real-Time PCR System (Applied Biosystems, United States) using FAST START SYBR green master mix according to the manufacturer's instructions. The following procedure was used: $95^{\circ} \mathrm{C}$ for $10 \mathrm{~min}$ and one cycle for cDNA denaturation, $95^{\circ} \mathrm{C}$ for $10 \mathrm{~s}, 60^{\circ} \mathrm{C}$ for $20 \mathrm{~s}, 36$ cycles for amplification, and one cycle for melting curve analysis (from 60 to $95^{\circ} \mathrm{C}$ ) to verify the presence of a single product. qPCR was performed in triplicate for each sample. The relative expression levels were measured using Relative Expression Software Tool (REST).

\section{Statistical Analysis}

All results are presented in the text as mean \pm standard error. Significant differences $(P<0.01)$ in the OD value, dry cell weight, chlorophyll fluorescence, and pigment content under the $\mathrm{A}(n=3), \mathrm{H}(n=3), \mathrm{AH}(n=3)$, and $\mathrm{C}(n=3)$ conditions were tested by ANOVA using the stats package in $\mathrm{R}$ software ( $\mathrm{R}$ Core Team, 2014). Significant $(P<0.01)$ differences in the Bray-Curtis distances of differentially transcribed genes under the $\mathrm{A}(n=3), \mathrm{H}(n=3), \mathrm{AH}(n=3)$, and $\mathrm{C}(n=3)$ conditions were determined by permutational multivariate analysis of variance (MANOVA) in Primer-e (see text footnote $2)$. Significant $(P<0.01)$ differences in qPCR-measured genes under the $\mathrm{A}(n=3), \mathrm{H}(n=3), \mathrm{AH}(n=3)$, and $\mathrm{C}(n=3)$ conditions were calculated using the pair-wise fixed reallocation randomization test in REST.

\footnotetext{
${ }^{2} \mathrm{http}: / /$ www.primer-e.com/
} 


\section{RESULTS}

\section{Growth and Morphological Responses of S. hainanensis to $\mathrm{H}, \mathrm{A}$, and $\mathrm{AH}$}

The cell concentration, as measured by $\mathrm{OD}_{750}$ (Figure 1A) and cell dry weight (Figure 1B) of S. hainanensis, was significantly promoted by elevated temperature $(\mathrm{H}, n=3)$, acidification (A, $n=3)$, and the combined treatment ( $\mathrm{AH}, n=3)$ compared with the control (C, $n=3 ; P<0.01)$. The growth rate of S. hainanensis increased 1.05 -fold but decreased 1.04-fold in the combined treatment compared with individual elevated temperature (AH-VS-H, $P<0.01)$ and acidification (AHVS-A, $P<0.01$ ), respectively (Supplementary Figure 5). In addition, chlorophyll fluorescence (Figure 1C) and pigment content (Figure 1D) showed similar variation trends with the algal growth of S. hainanensis under different conditions.

The features of the cell morphology of $S$. hainanensis under different conditions were documented (Figure 2). The cell wall of $S$. hainanensis was furrowed (A2-A4), and the shape of the chloroplast changed (i.e., the volume of chloroplast became larger under acidification and warming conditions; B2-B4). More starch granules under acidification and warming conditions were observed (B2-B4). Moreover, the sporangium of $S$. hainanensis was observed under acidification condition (C1-C4).

\section{Transcriptomic Profiles of S. hainanensis Response to $\mathrm{H}, \mathrm{A}$, and $\mathrm{AH}$}

A total of 12 transcriptomic sequencing libraries were generated for the four conditions ( $\mathrm{C}, \mathrm{H}, \mathrm{A}$, and $\mathrm{AH}$ ) with three biological replicates. These libraries were sequenced with an Illumina platform with an output of $88.36 \mathrm{G}$ clean reads (an average of 7.36 $\mathrm{G}$ reads per sample) (Supplementary Table 2). The clean reads were pooled together and assembled into 95,827 unique genes, with an average length of 1,277 bp and a N50 value of 3,768 bp (Supplementary Table 3).

The PCoA analysis revealed that the gene transcription of S. hainanensis was significantly different under the $\mathrm{C}, \mathrm{H}, \mathrm{A}$, and AH conditions (Figure 3, MANOVA, $P<0.001$ ). The PCoA analysis showed the following order of the effect of different conditions on gene transcription: A-VS-C $>$ AH-VS-H $>\mathrm{H}-$ VS-C. Among the detected genes, 688 genes were significantly differentially transcribed, and more than half of these genes had unknown functions (Supplementary File 1).
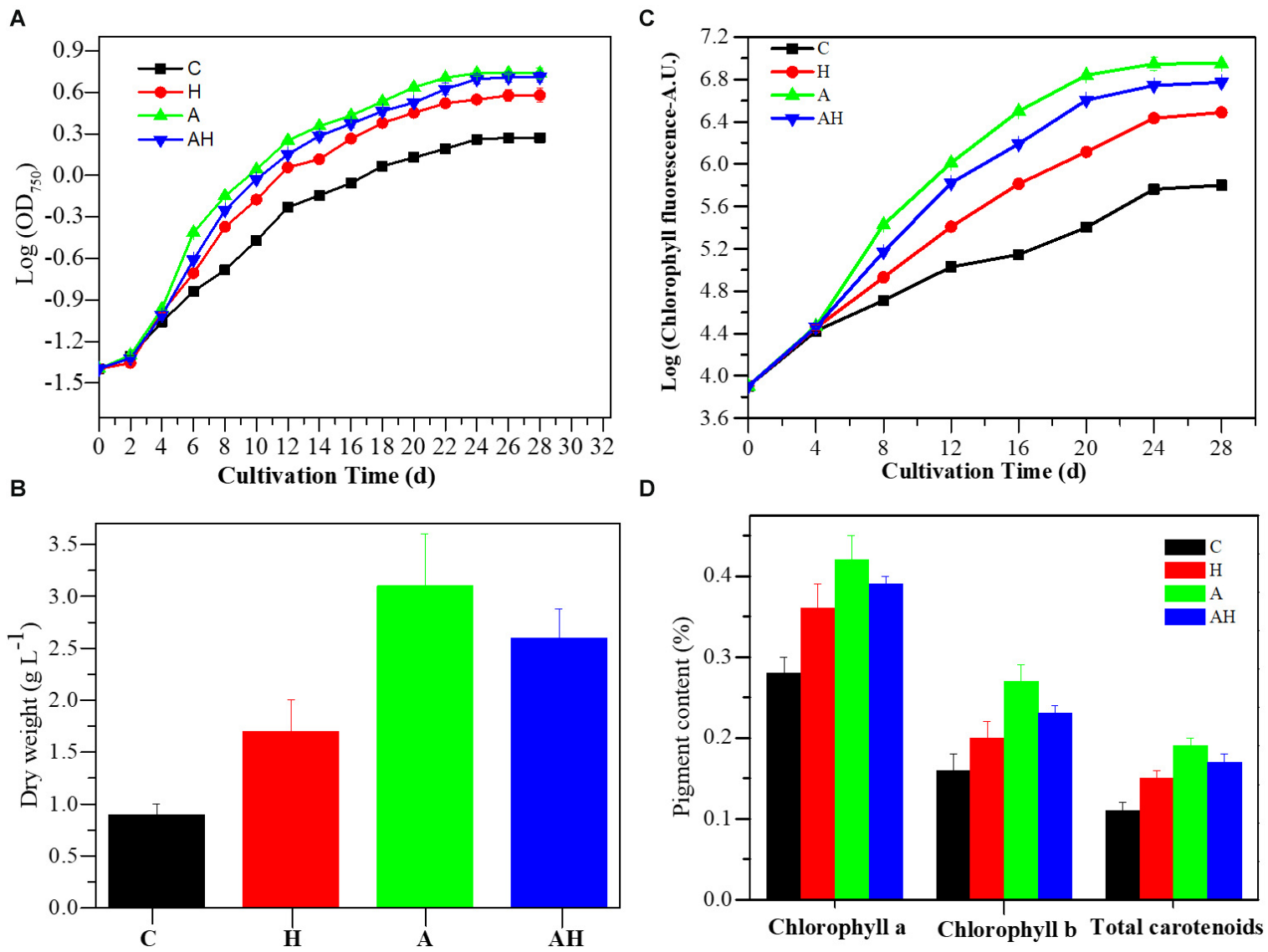

FIGURE 1 | Growth characteristics of Symbiochlorum hainanensis in response to acidification and warming conditions. Growth curves (A), cellular dry weight [(B) day 20], chlorophyll fluorescence (C), and pigment content [(D) day 20] of $S$. hainanensis under the control (in situ temperature) $-\mathrm{C}(n=3)$, elevated temperature $-\mathrm{H}$ $(n=3)$, acidification $-\mathrm{A}(n=3)$, and combined treatment $-\mathrm{AH}(n=3)$. All results are presented in the text as mean \pm standard error. 

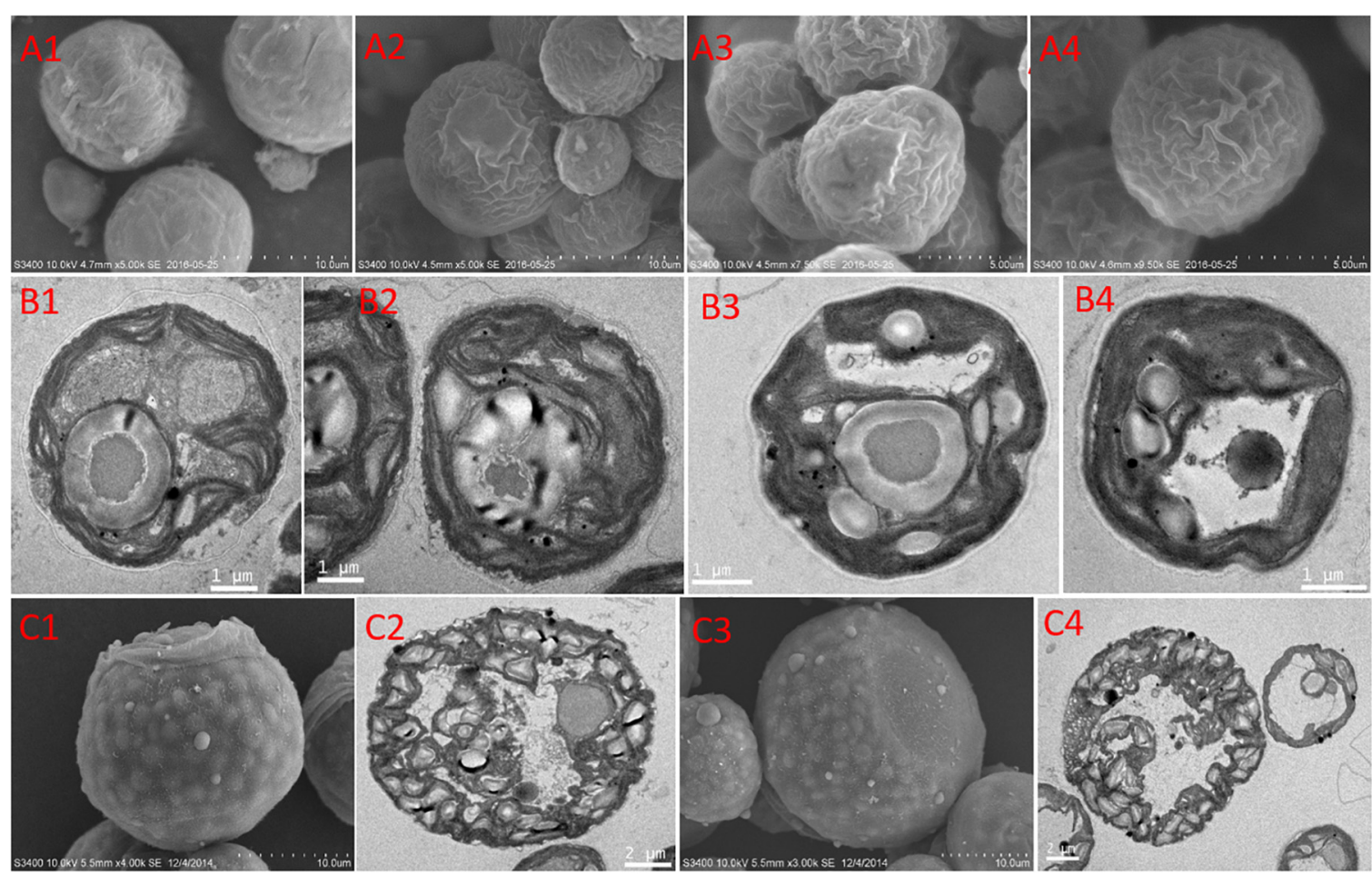

FIGURE 2 | Morphological characteristics of Symbiochlorum hainanensis in response to acidification and warming. Scanning electron microscopic presentations of the vegetative cells of $S$. hainanensis under the control (A1), elevated temperature (A2), acidification (A3), and combined treatment (A4). Transmission electron microscopic presentations of vegetative cells of S. hainanensis under the control (B1), elevated temperature (B2), acidification (B3), and combined treatment (B4). Scanning and transmission electron microscopic presentations of aplanosporangiums of $\mathrm{S}$. hainanensis under acidification conditions (C1-C4).
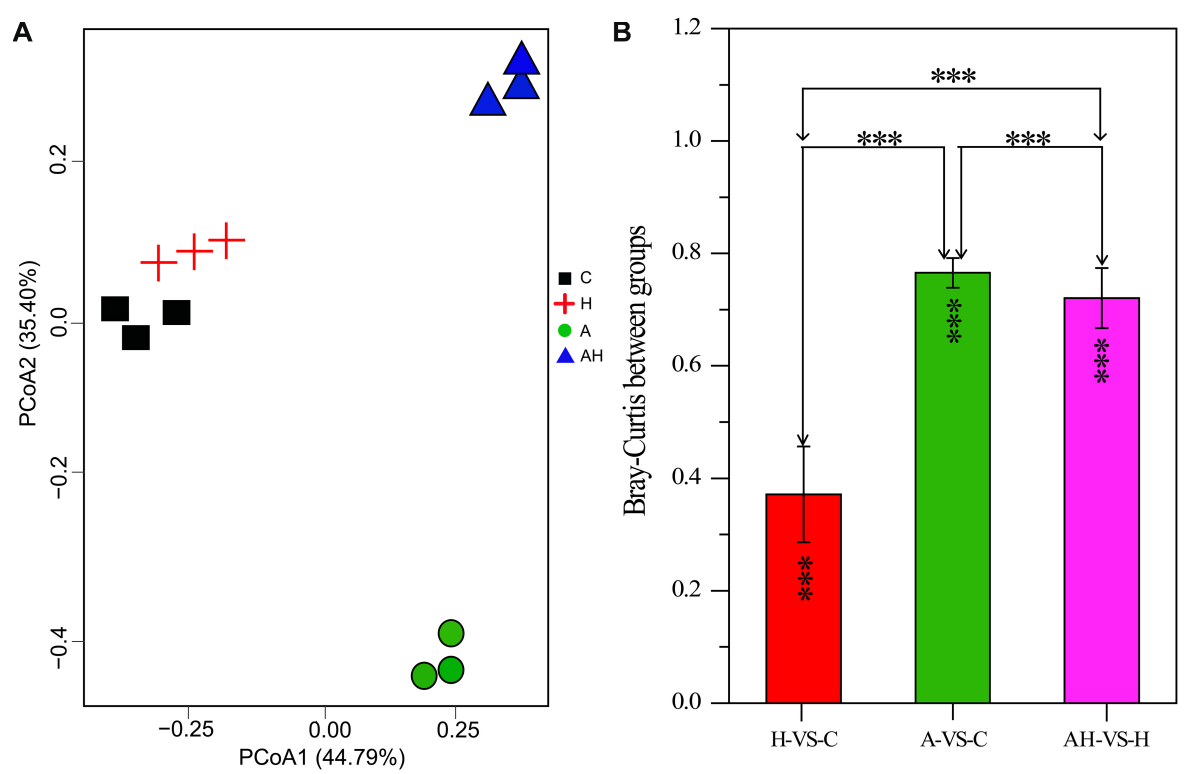

FIGURE 3 | Plots of principal coordinate analysis (A) and permutational multivariate analysis of variance analysis (B) of differentially transcribed genes under different conditions: control-C $(n=3)$, elevated temperature $-\mathrm{H}(n=3)$, acidification $-\mathrm{A}(n=3)$, and combined treatment $-\mathrm{AH}(n=3)$. Significant differences $(P<0.01)$ in Bray-Curtis distances of differentially transcribed genes under different conditions were determined using Primer-e. All results are presented in the text as mean \pm standard error. 
The genes related to photosynthesis, $\mathrm{CO}_{2}$ biofixation, carbohydrate metabolism, cell cycle and control, nutrient input, transport and metabolism, stress response, and intracellular homeostasis were differentially transcribed under acidification and warming conditions (Figure 4). Other genes involved in flagella-related components, extracellular matrix (fasciclin-like protein, glycoprotein of tenascin, and the expansin superfamily of proteins), and transcriptional regulation also changed under different conditions (Supplementary File 1).

To validate the RNA-seq results, several key genes were selected for qPCR analysis. The results exhibited the same trends as the results of RNA-seq, confirming the reliability of our present analysis (Supplementary Table $\mathbf{1}$ ).

\section{Photosynthesis-Related Gene Responses to $\mathrm{H}, \mathrm{A}$, and $\mathrm{AH}$}

The transcription of genes related to photosynthesis was minimally affected by elevated temperature (H-VS-C) (Figure 4), while gene transcription was obviously affected by acidification (A-VS-C) and the combined treatment (AH) (Figures 4-6). Specifically, nearly all differentially transcribed genes related to photosynthesis were significantly down-regulated under the combined treatment. For example, the genes of psaA, psaJ, and $y c f 3$ involved in photosystem I, $p s b B, p s b C, p s b E, p s b H$, $p s b P$, and $p s b S$ involved in photosystem II, $l h c B, \operatorname{chl} B, \operatorname{chl} P$, and chl11 involved in light-harvesting complex (LHC) protein, and atpA and atpB involved in photosynthetic ATP synthesis were down-regulated more than 1-15-fold by the combined treatment $(\mathrm{AH})$ (Figures 4, 6). In addition, the $l c i$ and cah1 genes encoding low $\mathrm{CO}_{2}$-inducible protein and soluble carbonic anhydrase related to carbon acquisition by $\mathrm{CO}_{2}$ concentrating mechanism (CCM) were significantly down-regulated more than fourfold by individual acidification and the combined treatment (Figures 4-6).

\section{Carbohydrate Metabolism-Related Gene Responses to $\mathrm{H}, \mathrm{A}$, and $\mathrm{AH}$}

Acidification and elevated temperature had different effects on the genes related to the carbohydrate metabolism of S. hainanensis (Figures 4-6). Almost all the differentially transcribed genes involved in carbohydrate metabolism were upregulated by acidification (A-VS-C), while most were minimally affected by elevated temperature and the combined treatment (both H-VS-C and AH-VS-H). Compared with the control (C), individual acidification (A) caused the genes $f b a, c l s a 11, u g d h 3$, ugdh4, man1, man5, msp130, mindh, and aox4 related to the citric acid cycle (TCA), cell wall polysaccharide synthesis, and $\beta$ oxidation of fatty acids to be significantly up-regulated more than threefold. However, the transcription of those genes was downregulated approximately $1-17$-fold by the combined treatment (AH).

\section{Cell and Life Cycle-Related Gene Responses to $\mathrm{H}, \mathrm{A}$, and $\mathrm{AH}$}

Elevated temperature $(\mathrm{H})$ also had a minimal effect on the transcription of genes involved in the cell and life cycles.
However, almost all of these genes were up-regulated by individual acidification (A-VS-C), while most of them were down-regulated by the combined treatment (AH-VS-H) (Figures 4-6). Genes encoding DUF724 domain-containing protein and circumsporozoite protein related to sporulation were up-regulated by both individual acidification $(\mathrm{A})$ and the combined treatment $(\mathrm{AH})$. Specifically, the gene encoding DUF724 domain-containing protein was up-regulated approximately 66-fold by individual acidification (A). In addition, the key gene $f t s Z$, which is involved in chloroplast division, was significantly up-regulated by $\mathrm{A}, \mathrm{H}$, and $\mathrm{AH}$ compared with the control (C).

\section{Nutrient Transport- and Metabolism-Related Gene Responses to $H, A$, and $A H$}

The transcription of genes related to nutrient transport and metabolism is illustrated in Figures 4-6. Genes encoding alkaline phosphatase and ABC-type phosphate transporter involved in phosphate metabolism were up-regulated more than 10fold, whereas genes encoding $\mathrm{NO}_{3}{ }^{-}$transporter and nitrate reductase involved in nitrogen metabolism were down-regulated over threefold under elevated temperature (H-VS-C). Under the combined treatment $(\mathrm{AH})$, genes involved in nitrogen and phosphate metabolism were up-regulated over threefold relative to the acidification treatment (A). In addition, the gene encoding transferrin involved in $\mathrm{Fe}^{3+}$ transporter showed a higher transcription under the control (C) and elevated temperature $(\mathrm{H})$ conditions than under the other conditions, and it was significantly down-regulated approximately fivefold by acidification (A) and the combined treatment $(\mathrm{AH})$.

\section{Stress- and Intracellular Homeostasis-Related Gene Responses to $H, A$, and $A H$}

Genes encoding glutathione S-transferase, catalase isozyme, UvrB/uvrC motif, heat shock $22-\mathrm{kDa}$ protein, and chaperones were differentially transcribed under single acidification (A) or elevated temperature condition (H) (Figures 4-6). Specifically, the transcription of these genes was up-regulated more than twofold by the combined treatment $(\mathrm{AH})$ than by individual acidification (A), except for one gene encoding chaperone DnaJ. Moreover, genes related to ubiquitination processes were highly transcribed under different conditions.

\section{DISCUSSION}

In this study, we mainly explored the growth, morphology, and molecular level response of $S$. hainanensis, a recently discovered coral-associated thermo-tolerant alga, to future ocean acidification and warming conditions by culturing it under two temperature settings $\left(\sim 26.0\right.$ and $\left.\sim 32.0^{\circ} \mathrm{C}\right)$ crossed with two $\mathrm{pH}$ levels $(\sim 8.16$ and $\sim 7.81)$ in a 28 -day lab-scale experiment. We found that this thermo-tolerant alga exhibited a positive growth response to individual acidification, elevated 


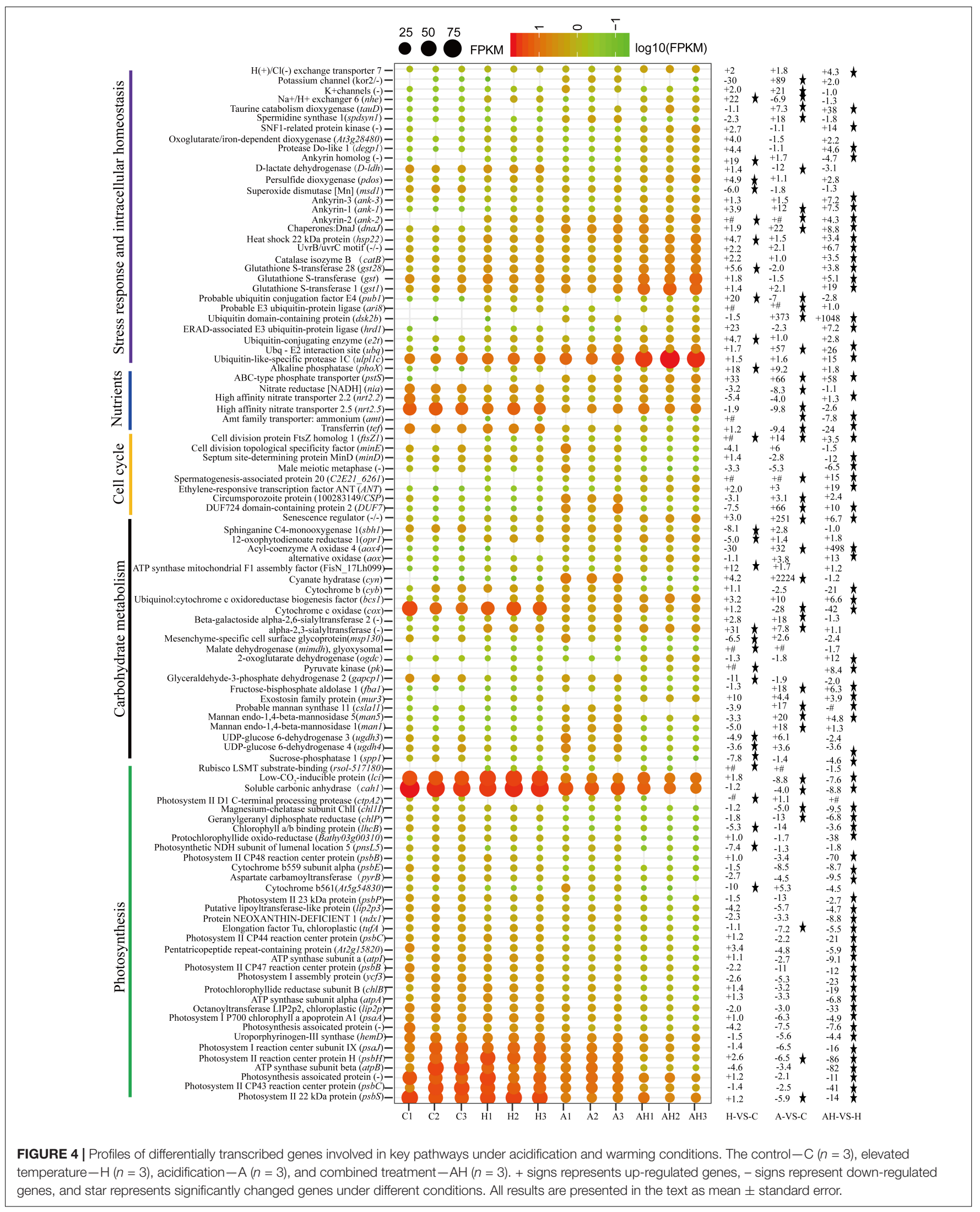




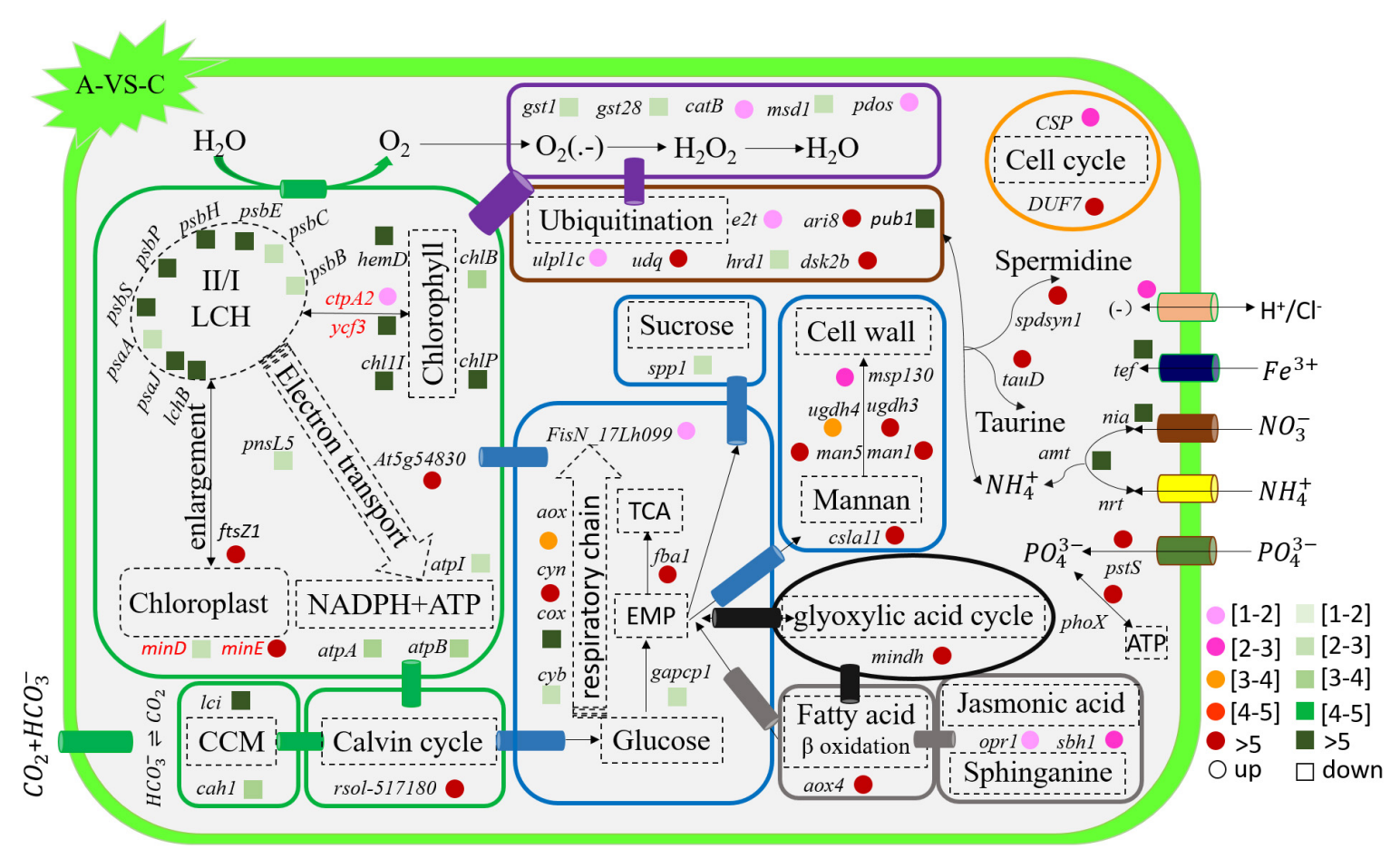

FIGURE 5 | Schematic summary of the gene functions affected by acidification compared with the control $(n=3)$ of in situ temperature ( $n=3)$. All results are presented in the text as mean \pm standard error.

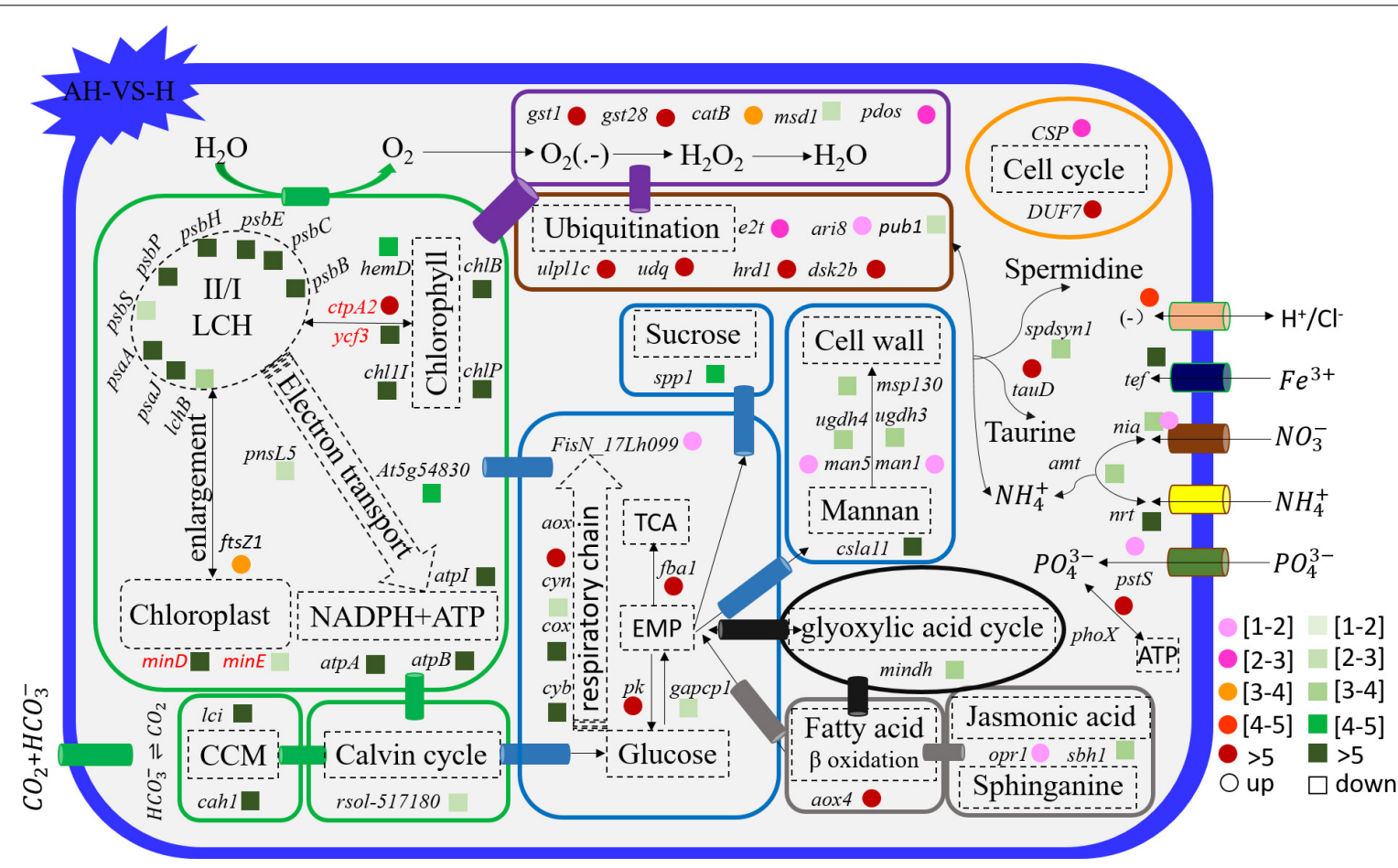

FIGURE 6 | Schematic summary of the gene functions affected by the combined treatment $(n=3)$ compared with elevated temperature $(n=3)$. All results are presented in the text as mean \pm standard error. 
temperature, and the combined treatment. We observed a nosuperimposition effect of individual acidification and elevated temperature on the growth of S. hainanensis compared with the combined treatment of acidification and elevated temperature. Interestingly, our present data indicated that the chloroplast enlargement (possibly controlled by the fts $Z$ gene) along with the increase of chlorophyll fluorescence and pigment content might be a universal mechanism for the stimulative growth of S. hainanensis under ocean acidification and warming conditions, implying the predominance of $S$. hainanensis in its associated corals and/or coral reef areas in the future. This study provides novel insights into the growth, morphology, and molecularlevel responses of thermo-tolerant algae to ocean warming and acidification conditions.

The stimulative growth response of S. hainanensis to ocean acidification reported in this study is consistent with the previous studies in several species of cyanobacteria, diatoms, and dinoflagellates (Brading et al., 2011; Wu et al., 2014; Walworth et al., 2016; Huang et al., 2018). The enhanced growth may be attributed to more carbon resources and down-regulated CCMs (an efficient process needs energy and resources for $\mathrm{CO}_{2}$ fixation by algae) caused by the increasing partial pressure of $\mathrm{CO}_{2}\left(p \mathrm{CO}_{2}\right)$ in seawater under acidification (Riebesell et al., 1993; Tortell et al., 2008). Our transcriptomic results also showed that two genes encoding low $\mathrm{CO}_{2}$-inducible protein $(l c i)$ and soluble carbonic anhydrase (cah1) associated with CCMs were significantly down-regulated by acidification. Although the genes encoding RubisCO for $\mathrm{CO}_{2}$ fixation were not differentially transcribed in S. hainanensis under acidification, one gene encoding RubisCO LSMT was significantly up-regulated. RubisCO LSMT was reported to exhibit methyltransferase activity toward RubisCO (Ying et al., 1999); thus, we propose that the up-regulation of the gene encoding RubisCO LSMT might be involved in the regulation of $\mathrm{CO}_{2}$ fixation in $S$. hainanensis under acidification. In addition, we observed that acidification enhanced the transcription of genes related to cell activity and growth (i.e., sucrose and cell wall polysaccharide synthesis, EMP, TCA, glyoxylic acid cycle, $\beta$-oxidation of fatty acid, and cyanideresistant respiration), which might contribute to the enhanced growth of S. hainanensis as well. Similar results were also reported in higher plants under elevated $\mathrm{CO}_{2}$ or stresses (Solomos, 1977; Li et al., 2008). Notably, our results showed that almost all genes involved in photosynthesis (i.e., $p s b B-p s b S$ of photosynthetic II, $p s a A$ and $p s a J$ of photosynthetic I, and $l \operatorname{ch} B$ of LHC) were down-regulated by acidification. According to one previous study of diatom (Goldman et al., 2017), a likely reason for the variability in the response of $S$. hainanensis (excluding potential modulation by other environmental factors, i.e., temperature) to acidification is that the increasing $\mathrm{pCO}_{2}$ (carbon resource) and the concomitantly decreasing $\mathrm{pH}$ (acidification) separately have different effects on the growth and photosynthesis. Interestingly, we observed that the chlorophyll fluorescence and pigment content of $S$. hainanensis significantly increased under acidification. Concomitantly, enlargement of chloroplast and significant up-regulation of one key gene $f t s Z$ (encoding cell division protein homolog 1) for controlling chloroplast division and/or morphogenesis (Strepp et al., 1998; Wang et al., 2002) were observed under acidification in S. hainanensis. Therefore, we speculated that the significant up-regulation of fts $Z$ gene might contribute to the enlargement of chloroplast and the enhancement of chlorophyll fluorescence and pigment content of S. hainanensis under acidification.

The present results showed that the growth of S. hainanensis was greatly promoted by an elevated temperature of $32^{\circ} \mathrm{C}$. To our knowledge, this was the first report of a positive response of marine algae to an elevated temperature up to $32^{\circ} \mathrm{C}$. A previous study suggested that marine algae may exhibit much lower optimal growth temperature than tropical seagrasses and macroalgae which showed optimal growth temperature ranging from 27 to $33^{\circ} \mathrm{C}$ (Koch et al., 2013). Biber (2007) reported that the biomass of Florida algae significantly decreased when the temperatures were above $31^{\circ} \mathrm{C}$. Fleshy, branching tropical macroalgae species maintain relatively consistent net productivity rates at $32^{\circ} \mathrm{C}$ (Mejia et al., 2012). The photosynthesis of the tropical Codium edule (macroalgae) was disrupted and inhibited at 32 and $35^{\circ} \mathrm{C}$, respectively (Lee and $\mathrm{Hsu}, 2010$ ). Even for the generally considered thermo-tolerant Symbiodiniaceae (Durusdinium spp.) associated with corals, both net growth and negative effect of photosynthesis at $32^{\circ} \mathrm{C}$ were reported (Karim et al., 2015). Notably, our results showed that S. hainanensis isolated from tropical reefs in the South China Sea exhibited a high optimal growth temperature of $32^{\circ} \mathrm{C}$, which was higher than those of previously reported algal species. In reality, $S$. hainanensis could maintain a rapid growth even when it was cultured at $35^{\circ} \mathrm{C}$. The transcriptomic results showed that, in addition to up-regulating genes involved in protein folding, oxidative stress, and ubiquitination processes, elevated temperature had a minimal effect on the transcription of genes involved in the basic metabolism of $S$. hainanensis, such as photosynthesis, carbohydrate metabolism, the cell cycle, and nutrient metabolism. As what previous studies have suggested for other organisms (Kumar et al., 2017; Ruocco et al., 2017), the up-regulation of genes related to protein folding (i.e., heat shock protein and chaperone) might contribute to the thermal acclimation of $S$. hainanensis. It is widely believed that the production of reactive oxygen species increases under elevated temperatures or other stresses, and plants/algae must activate their antioxidant defense mechanisms to protect themselves from oxidative damage (Ledford and Niyogi, 2005; Lazaro et al., 2016). Similarly, genes encoding glutathione S-transferase, catalase, and persulfide dioxygenase related to antioxidant defense mechanisms were up-regulated in S. hainanensis. The ubiquitination processes may also have aided in the ability of this alga to acclimate to high temperatures given the upregulation in the transcription of the respective genes, such as up-regulating genes encoding ubiquitin ligase (over 23fold) (Mayfield et al., 2014). In addition, the increase of chlorophyll fluorescence and pigment content, the enlargement of chloroplast, and the significant up-regulation of fts $Z$ gene encoding cell division protein homolog 1 were also observed under elevated temperature in S. hainanensis, which might also contribute to the enhanced growth of S. hainanensis under elevated temperature. 
Laboratory studies have shown that the effects of the combined treatment of elevated temperature and acidification on the growth of marine algae are species specific (Hyun et al., 2014; Gao et al., 2019). For example, the growth of the picoplanktonic cyanobacterium Synechococcus was promoted by the combined treatment, whereas elevated temperature and acidification had no effects on Prochlorococcus (Fu et al., 2007). Similarly, the combined treatment promoted the growth of the diatom Skeletonema (Kremp et al., 2012), but it had no obvious effects on Thalassiosira and Chaetoceros (Hyun et al., 2014). The growth of coccolithophore E. huxleyi was inhibited by the combined treatment (Listmann et al., 2016). Our present results indicated that the combination of elevated temperature and acidification $(\mathrm{AH})$ had a positive effect on the growth of $S$. hainanensis $(\mathrm{AH}-$ VS-C). Meanwhile, we observed no superimposition effect on the growth of $S$. hainanensis in response to acidification and elevated temperature alone, compared to the combined treatment.

For transcriptional profiles, the effects of individual acidification and warming conditions on the response of marine algae and terrestrial plant have been widely reported ( $\mathrm{Li}$ et al., 2008; Kumar et al., 2017; Ruocco et al., 2017). To our knowledge, however, data on the effect of the combined treatment of elevated temperature and acidification $(\mathrm{AH})$ on marine algae have not been reported, and we do not know the mechanisms involved. Differently from the no-superimposition effect in the growth of S. hainanensis, a superimposition effect of the individual elevated temperature $(\mathrm{H})$ and acidification $(\mathrm{A})$ on the gene transcription of $S$. hainanensis was observed under combined treatment $(\mathrm{AH})$. Meanwhile, our present transcriptomic data revealed a balanced strategy used by $S$. hainanensis for maintaining moderate growth under the combined treatment of elevated temperature and acidification (AH). For example, the transcription of genes related to photosynthesis, $\mathrm{CO}_{2}$ biofixation, and carbohydrate metabolism was inhibited, but genes related to antioxidant and ubiquitination processes were promoted under combined treatment $(\mathrm{AH})$ compared with individual elevated temperature (H) and acidification (A).

\section{CONCLUSION}

This study mainly describes the growth, morphology, and molecular response of $S$. hainanensis, a recently discovered coralassociated thermo-tolerant alga, to future ocean acidification and warming conditions. The promoted growth of S. hainanensis under these conditions suggests the strong acclimation of this alga to future ocean environmental changes. An antagonistic effect on the growth of $S$. hainanensis was observed between elevated temperature and acidification, which are involved in the balance of gene transcription related to basic metabolism and stress responses. The present data revealed that chloroplast

\section{REFERENCES}

Baker, A., Starger, C., and Mcclanahan, T. (2004). Corals' adaptive response to climate. Nature 430:74.

Biber, P. D. (2007). Hydrodynamic transport of drifting macroalgae through a tidal cut. Estuar. Coastal Shelf Sci. 74, 565-569. doi: 10.1016/j.ecss.2007.04.019 morphogenesis (possibly controlled by ftsZ gene) along with increasing chlorophyll fluorescence and pigment content might serve as a universal mechanism for promoting the growth of this alga under both acidification and warming conditions. This alga is also ecologically important because it is highly abundant in corals in the SCS, and the optimum growth temperature of $32^{\circ} \mathrm{C}$ for $S$. hainanensis isolated from bleached corals in the SCS is higher than those of the symbiotic Cladocopium spp. and Durusdinium spp. (thermal-sensitive and thermal-tolerant Symbiodiniaceae majorly associated with corals in the SCS). The present study provides novel and valuable data on the growth of $S$. hainanensis and improves the knowledge of the molecular functions underpinning the growth response of thermo-tolerant algae to future ocean acidification and warming. This study also lays a foundation for a further evaluation of the distribution and the ecological significance of S. hainanensis in coral-algae symbionts and/or coral reef areas.

\section{DATA AVAILABILITY STATEMENT}

The datasets presented in this study can be found in online repositories. The names of the repository/repositories and accession number(s) can be found in the article/Supplementary Material.

\section{AUTHOR CONTRIBUTIONS}

SG and ZL conceived and designed the experiments. SG and YX performed the cultivation experiment and sampling. SG performed the molecular and bioinformatic analyses. SG, XJ, and ZL wrote the manuscript. All the authors read and approved the final manuscript.

\section{FUNDING}

This work was funded by the Major National Scientific Research Project, China (2013CB956103) and the National Natural Science Foundation of China (41906135). This work was supported by the Key Special Project for Introduced Talents Team of Southern Marine Science and Engineering Guangdong Laboratory (Guangzhou; GML2019ZD0405).

\section{SUPPLEMENTARY MATERIAL}

The Supplementary Material for this article can be found online at: https://www.frontiersin.org/articles/10.3389/fpls.2020. 585202/full\#supplementary-material

Bolger, A. M., Lohse, M., and Usadel, B. (2014). Trimmomatic: a flexible trimmer for illumina sequence data. Bioinformatics 30, 2114-2120. doi: 10.1093/bioinformatics/btu170

Boyd, P., Collins, S., Dupont, S., Fabricius, K., Gattuso, J. P., and Havenhand, J. (2018). Experimental strategies to assess the biological ramifications of multiple drivers of ocean global ocean-a 
review. Global Change Biol. 24, 2239-2261. doi: 10.1111/gcb. 14102

Brading, P., Warner, M. E., Davey, P., Smith, D. J., Achterberg, E. P., and Suggett, D. J. (2011). Differential effects of ocean acidification on growth and photosynthesis among phylotypes of Symbiodinium (dinophyceae). Limnol. Oceanogr. 56, 927-938. doi: 10.4319/lo.2011.56.3.0927

Conesa, A., Götz, S., Garcíagómez, J. M., Terol, J., Talón, M., and Robles, M. (2005). Blast2go: a universal tool for annotation, visualization and analysis in functional genomics research. Bioinformatics 21, 3674-3676. doi: 10.1093/bioinformatics/ bti610

Cornwall, C. E., Revill, A. T., Hall-Spencer, J. M., Milazzo, M., Raven, J. A., and Hurd, C. L. (2017). Inorganic carbon physiology underpins macroalgal responses to elevated $\mathrm{CO}_{2}$. Sci. Rep. 7:46297.

Cornwall, C. E., Revill, A. T., and Hurd, C. L. (2015). High prevalence of diffusive uptake of $\mathrm{CO}_{2}$ by macroalgae in a temperate subtidal ecosystem. Photosynth. Res. 124, 181-190. doi: 10.1007/s11120-015-0114-0

Dere, S., Gunes, T., and Sivaci, R. (1998). Spectrophotometric determination of chlorophyll-a, b and total carotenoid contents of some algae species using different solvents. Botany 22, 13-17.

Falkowski, P. G., and Raven, J. A. (2013). Aquatic Photosynthesis. Princeton, NY: Princeton University Press.

Fautin, D. G., and Buddemeier, R. W. (2004). Adaptive bleaching: a general phenomenon. Hydrobiologia 530-531, 459-467. doi: 10.1007/978-1-40202762-8_52

Feely, R. A., Doney, S. C., and Cooley, S. R. (2009). Ocean acidification: Present conditions and future changes in a high- $\mathrm{CO}_{2}$ world. Oceanography 22, 36-47. doi: 10.5670/oceanog.2009.95

Fu, F. X., Warner, M. E., Zhang, Y., Feng, Y., and Hutchins, D. A. (2007). Effects of increased temperature and $\mathrm{CO}_{2}$ on photosynthesis, growth, and elemental ratios in marine Synechococcus and Prochlorococcus (Cyanobacteria). J. Phycol. 43, 485-496. doi: 10.1111/j.1529-8817.2007.00355.x

Gao, G., Clare, A. S., Rose, C., and Caldwell, G. S. (2017). Eutrophication and warming-driven green tides (Ulva rigida) are predicted to increase under future climate change scenarios. Mar. Pollut. Bull. 114, 439-447. doi: 10.1016/j. marpolbul.2016.10.003

Gao, K. S., Aruga, Y., Asada, K., Ishihara, T., Akano, T., and Kiyohara, M. (1993). Calcification in the articulated coralline alga Corallina pilulifera, with special reference to the effect of elevated $\mathrm{CO}_{2}$ concentration. Mar. Biol. 117, 129-132. doi: $10.1007 /$ bf00346434

Gao, K. S., Beardall, J., Häder, D. P., Hall-Spencer, J. M., Gao, G., and Hutchins, D. A. (2019). Effects of ocean acidification on marine photosynthetic organisms under the concurrent influences of warming, UV radiation, and deoxygenation. Front. Mar. Sci. 6:322.

Gao, K. S., and Campbell, D. (2014). Photophysiological responses of marine diatoms to elevated $\mathrm{CO}_{2}$ and decreased $\mathrm{pH}$ : a review. Funct. Plant Biol. 41, 449-459. doi: 10.1071/fp13247

Goldman, J. A. L., Bender, M. L., and Morel, F. M. M. (2017). The effects of pH and $\mathrm{pCO}_{2}$ on photosynthesis and respiration in the diatom Thalassiosira weissflogii. Photosynth. Res. 132, 1-11. doi: 10.1007/978-3-319-23534-9_1

Gong, S. Q., Li, Z. Y., Zhang, F. L., Xiao, Y. L., and Chen, H. (2018). Symbiochlorum hainanensis, gen. et sp. nov. (ulvophyceae, chlorophyta) isolated from bleached corals living in the south china sea. J. Phycol. 54, 811-817. doi: 10.1111/jpy. 12779

Gong, S. Q., Xu, L. J., Yu, K. F., Zhang, F. L., and Li, Z. Y. (2019). Differences in Symbiodiniaceae communities and photosynthesis following thermal bleaching of massive corals in the northern part of the South China Sea. Mar. Pollut. Bull. 144, 196-204. doi: 10.1016/j.marpolbul.2019.04.069

Grabherr, M. G., Haas, B. J., Yassour, M., Levin, J. Z., Thompson, D. A., and Amit, I. (2011). Full-length transcriptome assembly from RNA-seq data without a reference genome. Nat. Biotechnol. 29:644. doi: 10.1038/nbt. 1883

Haas, B. J., Papanicolaou, A., Yassour, M., Grabherr, M., Blood, P. D., and Couger, M. B. (2013). De novo transcript sequence reconstruction from RNA-seq using the trinity platform for reference generation and analysis. Nat. Protoc. 8, 1494-1512. doi: 10.1038/nprot.2013.084

Hoegh-Guldberg, O., and Bruno, J. F. (2010). The impact of climate change on the world's marine ecosystems. Science 328, 1523-1528. doi: 10.1126/science. 1189930
Huang, Y. B., Liu, X., Laws, E. A., Chen, B. Z., Li, Y., and Xie, Y. (2018). Effects of increasing atmospheric $\mathrm{CO}_{2}$ on the marine phytoplankton and bacterial metabolism during a bloom: a coastal mesocosm study. Sci. Total Environ. 633, 618-629. doi: 10.1016/j.scitotenv.2018.03.222

Hyun, B., Choi, K. H., Jang, P. G., Jang, M. C., Lee, W. J., Moon, C. H., et al. (2014). Effects of increased $\mathrm{CO}_{2}$ and temperature on the growth of four diatom species (Chaetoceros debilis, Chaetoceros didymus, Skeletonema costatum and Thalassiosira nordenskioeldii) in laboratory experiments. J. Environ. Sci. Int. 23, 1003-1012. doi: 10.5322/jesi.2014.23.6.1003

IPCC (2014). Climate change 2014: Impacts, Adaptation, and Vulnerability. Part B: Regional Aspects Contribution of Working Group II to the Fifth Assessment Report of the Intergovernmental Panel on Climate Change. Geneva: IPCC.

Jin, P., Ding, J. C., Xing, T., Riebesell, U., and Gao, K. S. (2017). High levels of solar radiation offset impacts of ocean acidification on calcifying and noncalcifying strains of Emiliania huxleyi. Mar. Ecol. Prog. Ser. 568, 47-58. doi: 10.3354/meps12042

Johnson, M. D., Price, N. N., and Smith, J. E. (2014). Contrasting effects of ocean acidification on tropical fleshy and calcareous algae. PeerJ 2:411.

Karim, W., Nakaema, S., and Hidaka, M. (2015). Temperature effects on the growth rates and photosynthetic activities of Symbiodinium cells. J. Mar. Sci. Eng. 3, 368-381. doi: 10.3390/jmse3020368

Koch, M., Bowes, G., Ross, C., and Zhang, X. H. (2013). Climate change and ocean acidification effects on seagrass and marine macroalgae. Global Change Biol. 19, 103-132. doi: 10.1111/j.1365-2486.2012.02791.x

Kremp, A., Godhe, A., Egardt, J., Dupont, S., Suikkanen, S., Casabianca, S., et al. (2012). Intraspecific variability in the response of bloom-forming marine microalgae to changed climate conditions. Ecol. Evolut. 2, 1195-1207. doi: 10.1002/ece3.245

Kumar, A., Castellano, I., Patti, F. P., Delledonne, M., and Buia, M. C. (2017). Molecular response of Sargassum vulgare to acidification at volcanic $\mathrm{CO}_{2}$ ventsinsights from de novo transcriptomic analysis. Mol. Ecol. 26, 2276-2290. doi: $10.1111 /$ mec. 14034

Lazaro, M. G., Juan, M. R., Dattolo, E., Rocio, G. M., and Gabriele, P. (2016). Physiological and molecular evidence of differential short-term heat tolerance in mediterranean seagrasses. Sci. Rep. 6:28615.

Ledford, H. K., and Niyogi, K. K. (2005). Singlet oxygen and photo-oxidative stress management in plants and algae. Plant Cell Environ. 28, 1037-1045. doi: 10.1111/j.1365-3040.2005.01374.x

Lee, T. C., and Hsu, B. D. (2010). Disintegration of the cells of siphonous green alga Codium edule (bryopsidales, chlorophyta) under mild heat stress. J. Phycol. 45, 348-356. doi: 10.1111/j.1529-8817.2009. 00656.x

Li, B., and Dewey, C. N. (2011). RSEM: accurate transcript quantification from RNA seq data with or without a reference genome. BMC Bioinform. $12: 323$.

Li, P., Ainsworth, E. A., Leakey, A. D., Ulanov, A., Lozovaya, V., Ort, D. R., et al. (2008). Arabidopsis transcript and metabolite profiles: ecotype-specific responses to open-air elevated $\left[\mathrm{CO}_{2}\right]$. Plant Cell Environ. 31, 1673-1687. doi: 10.1111/j.1365-3040.2008.01874.x

Listmann, L., Leroch, M., Schlüter, L., Thomas, M. K., and Reusch, T. B. H. (2016). Swift thermal reaction norm evolution in a key marine phytoplankton species. Evolut. Appl. 9, 1156-1164. doi: 10.1111/eva. 12362

Martin, S., and Hall-Spencer, J. M. (2017). "Effects of ocean warming and acidification on rhodolith/maërl beds," in Rhodolith/Maërl Beds: A Global Perspective, eds R. Riosmena-Rodríguez, W. Nelson, and J. Aguirre (Cham: Springer), 55-85. doi: 10.1007/978-3-319-29315-8_3

Mayfield, A. B., Wang, Y. B., Chen, C. S., Lin, C. Y., and Chen, S. H. (2014). Compartment-specific transcriptomics in a reef-building coral exposed to elevated temperatures. Mol. Ecol. 23, 5816-5830. doi: 10.1111/mec.12982

Mejia, A. Y., Puncher, G. N., and Engelen, A. H. (2012). "Macroalgae in tropical marine coastal systems," in Seaweed Biology. Ecological Studies (Analysis and Synthesis), Vol. 219, eds C. Wiencke and K. Bischof (Berlin: Springer).

Moriya, Y., Itoh, M., Okuda, S., Yoshizawa, A. C., and Kanehisa, M. (2007). KAAS: an automatic genome annotation and pathway reconstruction server. Nucleic Acids Res. 35, 182-185.

R Core Team (2014). R: A Language and Environment for Statistical Computing. Vienna: R Core Team. 
Riebesell, U., Wolf-Gladrow, D. A., and Smetacek, V. (1993). Carbon dioxide limitation of marine phytoplankton growth rates. Nature 361, 249-251. doi: $10.1038 / 361249 \mathrm{a} 0$

Robinson, M. D., McCarthy, D. J., and Smyth, G. K. (2010). edgeR: a Bioconductor package for differential expression analysis of digital gene expression data. Bioinformatics 26, 139-140. doi: 10.1093/bioinformatics/ btp616

Rosic, N. N., and Hoegh-Guldberg, O. (2010). A method for extracting a highquality RNA from Symbiodinium sp. J. Appl. Phycol. 22, 139-146. doi: 10.1007/ s10811-009-9433-x

Ruocco, M., Musacchia, F., Olivé, I., Costa, M. M., Barrote, I., and Santos, R. (2017). Genomewide transcriptional reprogramming in the seagrass Cymodocea nodosa under experimental ocean acidification. Mol. Ecol. 26, 4241-4259.

Solomos, T. (1977). Cyanide-resistant respiration in higher plants. Ann. Rev. Physiol. 28, 279-297. doi: 10.1146/annurev.pp.28.060177.00 1431

Strepp, R., Scholz, S., Kruse, S., Speth, V., and Reski, R. (1998). Plant nuclear gene knockout reveals a role in plastid division for the homolog of the bacterial cell division protein ftsz, an ancestral tubulin. Proc. Natl. Acad. Sci. U.S.A. 95, 4368-4373. doi: 10.1073/pnas.95.8.4368

Tortell, P. D., Payne, C. D., Li, Y., Trimborn, S., Rost, B., Smith, W. O., et al. (2008). $\mathrm{CO}_{2}$ sensitivity of southern ocean phytoplankton. Geophys. Res. Lett. 35:L04605.

Walworth, N. G., Lee, M. D., Fu, F. X., Hutchins, D. A., and Webb, E. A. (2016). Molecular and physiological evidence of genetic assimilation to high $\mathrm{CO}_{2}$ in the marine nitrogen fixer Trichodesmium. Proc. Natl. Acad. Sci. U.S.A. 11, 7367-7374.
Wang, D., Kong, D. D., Ju, C. L., Hu, Y., He, Y. K., and Sun, J. S. (2002). Effects of tabacco plastid division genes NtFtsZ1 and NtFtsZ2 on the division and morphology of chloroplasts. Acta Bot. Sin. 44, 838-844.

Wernberg, T., Russell, B. D., Moore, P. J., Ling, S. D., Smale, D. A., and Campbell, A. (2011). Impacts of climate change in a global hotspot for temperate marine biodiversity and ocean warming. J. Exp. Mar. Biol. Ecol. 400, 7-16. doi: 10.1016/ j.jembe.2011.02.021

Wu, Y., Campbell, D. A., Irwin, A. J., Suggett, D. J., and Finkel, Z. V. (2014). Ocean acidification enhances the growth rate of larger diatoms. Limnol. Oceanogr. 59, 1027-1034. doi: 10.4319/lo.2014.59.3.1027

Ying, Z. T., Mulligan, R. M., Janney, N., and Houtz, R. L. (1999). Rubisco small and large subunit N-methyltransferases. J. Biol. Chem. 274, 36750-36756. doi: $10.1074 /$ jbc. 274.51 .36750

Zhang, F., Hong, H., Kranz, S. A., Shen, R., and Shi, D. (2019). Proteomic responses to ocean acidification of the marine diazotroph trichodesmium under ironreplete and iron limited conditions. Photosynth. Res. 142, 17-34. doi: 10.1007/ s11120-019-00643-8

Conflict of Interest: The authors declare that the research was conducted in the absence of any commercial or financial relationships that could be construed as a potential conflict of interest.

Copyright (c) 2020 Gong, Jin, Xiao and Li. This is an open-access article distributed under the terms of the Creative Commons Attribution License (CC BY). The use, distribution or reproduction in other forums is permitted, provided the original author(s) and the copyright owner(s) are credited and that the original publication in this journal is cited, in accordance with accepted academic practice. No use, distribution or reproduction is permitted which does not comply with these terms. 